\title{
Effects of Gender on the Number of Diseased Vessels and Clinical Outcome in Japanese Patients With Acute Coronary Syndrome
}

\author{
Kotaro Oe, MD; Masami Shimizu, MD; Hidekazu Ino, MD; \\ Masato Yamaguchi, MD; Hidenobu Terai, MD; Kenshi Hayashi, MD; \\ Masaru Kiyama, MD; Kenji Sakata, MD; Tatsumi Hayashi, MD; \\ Masaru Inoue, MD; Tomoya Kaneda, MD; Hiroshi Mabuchi, MD
}

\begin{abstract}
It has been reported that women with acute myocardial infarction (AMI) have a higher short-term mortality rate than men, but the reason is unclear and it is not known if it also applies to unstable angina pectoris (UAP). In addition, most previous studies have not presented angiographic findings. In the present study, the findings from 1,408 patients with AMI (group A: 361 women, 1,047 men) and 332 patients with UAP (group B: 103 women, 229 men) who underwent coronary angiography within 30 days of onset were analyzed. In both groups, the women were older and had a higher rate of hypertension and a lower rate of smoking than the men. There was no significant difference in Killip class or the number of diseased vessels between the women and men in both groups. Interventions (coronary angioplasty and coronary artery bypass grafting) were performed less frequently in the women than in the men $(87.2 \%$ vs $91.8 \%, \mathrm{p}=0.04)$ in group $\mathrm{A}$, but not in group B (80.6\% vs $81.2 \%$, NS). In both groups, the overall mortality rate during hospitalization was higher in women than in men (group A: $14.4 \%$ vs $7.4 \%, p<0.0001$, group B: $7.8 \%$ vs $1.7 \%, p=0.007$ ). Multivariate analysis revealed that female gender was an independent predictor of in-hospital mortality in group B (odds ratio (OR): 6.4, 95\% confidence interval (CI) 1.1-37.0, $\mathrm{p}=0.04$ ), but not in group A (OR: 1.7, 95\% CI 0.98-2.9, $\mathrm{p}=0.06)$. The independent predictors of in-hospital mortality, other than female gender were age, prior congestive heart failure, prior cerebrovascular disease and a higher Killip class in group A, and in both groups a higher number of diseased vessels. In conclusion, Japanese women with acute coronary syndromes present with similar angiographic findings and hemodynamics, but have a higher in-hospital mortality than male patients. Our results suggest that older age may be a potential explanation for the higher in-hospital mortality in women with AMI, but female gender itself may be an important predictor for it among those with UAP. (Circ J 2002; 66: 435-440)
\end{abstract}

Key Words: Acute myocardial infarction; Angiography; Gender; In-hospital mortality; Prognosis; Unstable angina pectoris

$\mathbf{I}$ thas been reported that women who present with acute myocardial infarction (AMI) have a worse in-hospital and long-term prognosis than men,-4 but other studies have reported that there is no significant difference in the mortality rate between men and women after adjusting for differences in age and other prognostic factors, $24-6$ Thus, the effect of gender on the outcome in patients with AMI is controversial.

Although there are many reports on AMI, the characteristics and outcome of women and men with unstable angina pectoris (UAP) have been rarely investigated, $, 7,8$ Hochman et al reported that among patients with UAP, female sex was an associated independent protective effect? Thus, the effect of gender may be different between AMI and UAP.

(Received March 28, 2001; revised manuscript received February 4, 2002; accepted February 8, 2002)

Molecular Genetics of Cardiovascular Disorders, Division of Cardiovascular Medicine, Graduate School of Medical Science, Kanazawa University, Kanazawa, Japan

Mailing address: Masami Shimizu, MD, Molecular Genetics of Cardiovascular Disorders, Division of Cardiovascular Medicine, Graduate School of Medical Science, Kanazawa University, 13-1 Takara-machi, Kanazawa 920-8640, Japan. E-mail: shimizu@med. kanazawa-u.ac.jp
However, there are several differences between the Japanese and Western populations with regard to treatment. In Japan, thrombolysis is used less frequently, and balloon angioplasty and stenting are the more common therapeutic strategies for acute coronary syndromes (ACS), which may lead to different outcomes in Japanese patients. In addition, coronary artery vasomotor reactivity differs between Japanese and Caucasian patients.,10 Although there are 2 large studies of Japanese patients with AMI, little information is available regarding the angiographic findings at presentation 6,11 and, moreover, reperfusion therapy was not commonly used in those studies. Thus, they may not reflect the current situation.

Most of the previous reports included patients who did not undergo coronary angiography with those who did!-5,7,11 so it is unclear whether a gender difference in the severity of coronary artery disease affects the clinical outcome of Japanese patients with ACS. Therefore, we investigated the effects of sex difference on clinical outcome and the number of diseased vessels in a group of Japanese patients with ACS who underwent coronary angiography. 


\begin{tabular}{|c|c|c|c|c|c|c|}
\hline & \multicolumn{3}{|c|}{$\begin{array}{c}\text { Group A } \\
\text { (Myocardial infarction) }\end{array}$} & \multicolumn{3}{|c|}{$\begin{array}{c}\text { Group B } \\
\text { (Unstable angina) }\end{array}$} \\
\hline & $\begin{array}{c}\text { Women } \\
(n=361)\end{array}$ & $\begin{array}{c}\text { Men } \\
(n=1,047)\end{array}$ & $p$ value & $\begin{array}{c}\text { Women } \\
(n=103)\end{array}$ & $\begin{array}{c}\text { Men } \\
(n=229)\end{array}$ & $p$ value \\
\hline Age (years) & $73 \pm 9$ & $63 \pm 12$ & $<0.0001$ & $72 \pm 9$ & $64 \pm 10$ & $<0.0001$ \\
\hline ST elevation & 83.9 & 86.6 & $N S$ & 8.2 & 17.4 & 0.04 \\
\hline Hypertension (\%) & 53.7 & 41.5 & $<0.0001$ & 62.1 & 44.1 & 0.006 \\
\hline Diabetes $(\%)$ & 30.1 & 33.0 & $N S$ & 43.7 & 36.6 & $N S$ \\
\hline Smoking (\%) & 14.6 & 70.0 & $<0.0001$ & 17.6 & 65.8 & $<0.0001$ \\
\hline Hypercholesterolemia (\%) & 35.6 & 32.6 & $N S$ & 45.0 & 36.9 & $N S$ \\
\hline Prior myocardial infarction (\%) & 7.6 & 10.3 & NS & 14.6 & 16.7 & NS \\
\hline Prior angina $(\%)$ & 33.6 & 34.6 & $N S$ & 47.6 & 56.3 & $N S$ \\
\hline Prior congestive heart failure (\%) & 5.3 & 3.9 & $N S$ & 3.9 & 4.8 & $N S$ \\
\hline Cerebrovascular disease (\%) & 10.9 & 10.4 & NS & 9.7 & 9.3 & NS \\
\hline Prior $C A B G(\%)$ & 0.6 & 2.1 & $N S$ & 6.8 & 3.5 & $N S$ \\
\hline Prior PTCA (\%) & 2.0 & 6.3 & 0.006 & 10.7 & 14.5 & $N S$ \\
\hline Peripheral vascular disease (\%) & 2.2 & 3.1 & $N S$ & 1.0 & 3.5 & NS \\
\hline
\end{tabular}

PTCA, percutaneous transluminal coronary angioplasty; $C A B G$, coronary artery bypass grafting.

Table 2 Hemodynamics at Presentation

\begin{tabular}{|c|c|c|c|c|c|c|}
\hline & \multicolumn{3}{|c|}{$\begin{array}{c}\text { Group A } \\
\text { (Myocardial infarction) }\end{array}$} & \multicolumn{3}{|c|}{$\begin{array}{c}\text { Group B } \\
\text { (Unstable angina) }\end{array}$} \\
\hline & $\begin{array}{l}\text { Women } \\
(n=361)\end{array}$ & $\begin{array}{c}\text { Men } \\
(n=1,047)\end{array}$ & $p$ value & $\begin{array}{l}\text { Women } \\
(n=103)\end{array}$ & $\begin{array}{c}\text { Men } \\
(n=229)\end{array}$ & $p$ value \\
\hline Heart rate (beats/min) & $79.6 \pm 21.5$ & $78.5 \pm 20.3$ & NS & $74.4 \pm 15.0$ & $71.6 \pm 14.7$ & $N S$ \\
\hline Systolic blood pressure $(\mathrm{mmHg})$ & $127.2 \pm 29.4$ & $127.4 \pm 27.1$ & $N S$ & $140.7 \pm 26.2$ & $136.3 \pm 23.3$ & $N S$ \\
\hline Killip class (\%) & & & $N S$ & & & $N S$ \\
\hline 1 & 63.2 & 68.1 & & 79.6 & 73.8 & \\
\hline 2 & 7.8 & 5.7 & & 0.9 & 3.9 & \\
\hline 3 & 3.9 & 2.3 & & 0.9 & 0.4 & \\
\hline 4 & 6.6 & 5.4 & & 0.9 & 0.9 & \\
\hline Unknown & 18.6 & 18.4 & & 17.5 & 21.0 & \\
\hline
\end{tabular}

\section{Methods}

\section{Patients}

We retrospectively analyzed data from 1,740 consecutive patients: 1,408 patients with AMI (group A: 361 women, 1,047 men) and 332 patients with UAP (group B: 103 women, 229 men). All patients underwent coronary angiography within 30 days of onset between January 1995 and December 1999 at the hospitals participating in this study. The electrocardiographic criteria included ST elevation or depression of more than $0.5 \mathrm{~mm}$ in 2 or more contiguous leads. AMI was considered to have occurred if the level of creatine kinase MB isoenzyme was above normal (and if it was at least $3 \%$ of the total creatine kinase level). If the creatine kinase $\mathrm{MB}$ level had not been measured, then the total creatine kinase level needed to be more than twice the upper limit of the normal range. Significant stenosis was defined as $\geq 75 \%$ reduction in coronary artery diameter. Angiographic success of coronary angioplasty was defined as achieving stenosis of less than $75 \%$ of the residual diameter with Thrombolysis In Myocardial Infarction (TIMI) trial grade 3 flow. The primary end-point of the study was in-hospital death.

\section{Statistical Analysis}

We compared the base-line characteristics and clinical outcomes between women and men. Statistical testing was performed using the chi-square test for categorical variables and unpaired $t$ test for continuous variables. We performed multivariable logistic regression analysis to identify the independent predictors of in-hospital mortality. Univariate predictors of in-hospital mortality with a $p$ value less than 0.1 were allowed to enter the model. We present the results as odds ratios (OR) and 95\% confidence intervals $(\mathrm{CI})$. A p value less than 0.05 was considered statistically significant.

\section{Results}

\section{Baseline Characteristics and Hemodynamics} at Presentation

The women were older than the men and had a higher rate of hypertension and a lower rate of smoking in both groups (Table 1). Heart rate, systolic blood pressure and Killip class were not different between the women and men in both groups (Table 2).

\section{Angiographic Characteristics and Intervention}

There were no significant differences in the number of diseased vessels and in the number of left main lesions between women and men in both groups (Table 3 ). Interventions (coronary angioplasty and coronary artery bypass grafting) were performed less frequently in women than in men in group A $(87.2 \%$ vs $91.8 \%, \mathrm{p}=0.04)$, but not in group B $(80.6 \%$ vs $81.2 \%$, NS). The rates of procedural success were not different between women and men in both groups (group A: $93.5 \%$ vs $93.0 \%$, NS, group B: $90.3 \%$ vs $90.4 \%, \mathrm{NS})$. 
Table 3 Angiographic Characteristics of the Patients

\begin{tabular}{|c|c|c|c|c|c|c|}
\hline & \multicolumn{3}{|c|}{$\begin{array}{c}\text { Group A } \\
\text { (Myocardial infarction) }\end{array}$} & \multicolumn{3}{|c|}{$\begin{array}{c}\text { Group B } \\
\text { (Unstable angina) }\end{array}$} \\
\hline & $\begin{array}{c}\text { Women } \\
(n=361)\end{array}$ & $\begin{array}{c}\text { Men } \\
(n=1,047)\end{array}$ & $p$ value & $\begin{array}{c}\text { Women } \\
(n=103)\end{array}$ & $\begin{array}{c}\text { Men } \\
(n=229)\end{array}$ & $p$ value \\
\hline No. of diseased vessels (\%) & & & $N S$ & & & NS \\
\hline 0 & 2.5 & 2.1 & & 5.8 & 6.1 & \\
\hline 1 & 46.0 & 49.9 & & 32.0 & 39.7 & \\
\hline 2 & 28.2 & 26.8 & & 25.3 & 21.8 & \\
\hline 3 & 21.6 & 17.8 & & 30.1 & 27.1 & \\
\hline Left main coronary disease (\%) & 1.7 & 3.4 & $N S$ & 6.8 & 5.3 & NS \\
\hline
\end{tabular}

\section{In-Hospital Outcomes}

In both groups, the overall mortality rate during hospitalization was higher in women than in men (Fig 1): $60.2 \%$ of deaths occurred within 7 days, $22.3 \%$ within 30 days, and the remainder after 30 days. In group A, the higher the number of diseased vessels, the higher the in-hospital mortality. In addition, women had higher mortality than men irrespective of the severity of disease. On the other hand, in group B, only women with 3-vessel disease or left main coronary disease had high in-hospital mortality (Fig 2). The rate of recurrent ischemic events and bleeding complications did not differ between the women and men in both groups (ischemic events: group A: $8.2 \%$ vs $6.0 \%$, NS, group B: $11.8 \%$ vs $11.8 \%$, NS; bleeding complication: group A: $1.5 \%$ vs $0.7 \%$, NS, group B: $0 \%$ vs $2.0 \%, \mathrm{NS}$ ).

\section{Cause of Death}

In both groups, the causes of death did not differ between the women and men (heart failure: group A: $55.8 \%$ (29 cases) vs $52.1 \%$ (38 cases), group B: $12.5 \%$ (1 case) vs $50.0 \%$ ( 2 cases); arrhythmia: group A: $9.6 \%$ (5 cases) vs 9.6\% (7 cases), group B: $0 \%$ vs $25.0 \%$ ( 1 cases); other causes: group A: $34.6 \%$ (18 cases) vs $38.3 \%$ (28 cases), group B: $87.5 \%$ ( 7 cases) vs $25.0 \%$ ( 1 case)). Other causes of death included cardiac rupture (8 cases), pneumonia (6 cases), renal failure (2 cases), cardiac tamponade of unknown cause (1 case), hepatic failure (1 case), mesenteric artery embolus (1 case), disseminated intravascular coagulation (1 case) and unknown (34 cases).

\section{Predictors of In-Hospital Mortality}

The univariate predictors of in-hospital mortality are

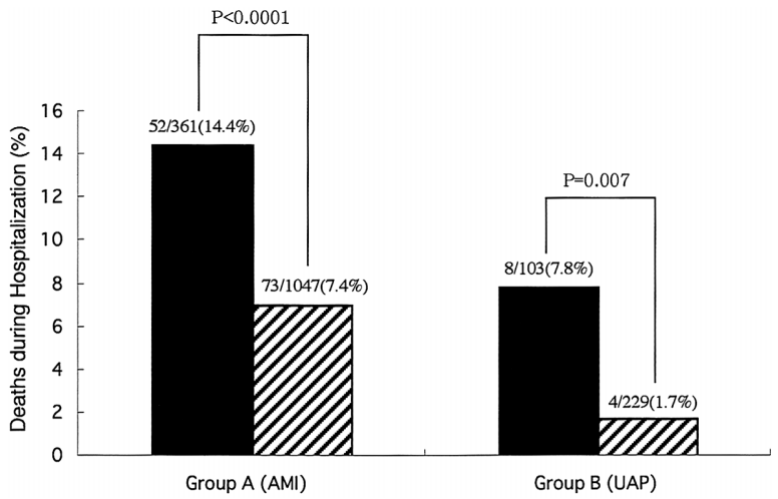

Fig 1. Rates of death during hospitalization for acute coronary syndromes among women and men. Closed bar, women; hatched bar, men. AMI, acute myocardial infarction; UAP, unstable angina pectoris. shown in Table4. After adjusting these variables, female gender was not an independent predictor of in-hospital mortality in group A, but was an independent predictor in group B. Multivariate analysis demonstrated that the independent predictors of in-hospital mortality other than female gender were higher age, prior congestive heart failure, prior cerebrovascular disease, higher Killip class in group A, and in both groups a higher number of diseased vessels. In group B, intervention was a negative predictor of in-hospital mortality (Table 5).

\section{Discussion}

Consistent with previous reports from Western populations, we found that Japanese women with ACS also had higher in-hospital mortality rates than men. The reasons given for the worse prognosis of women have been older age,-7,12 more comorbidities such as diabetes and hyperten-
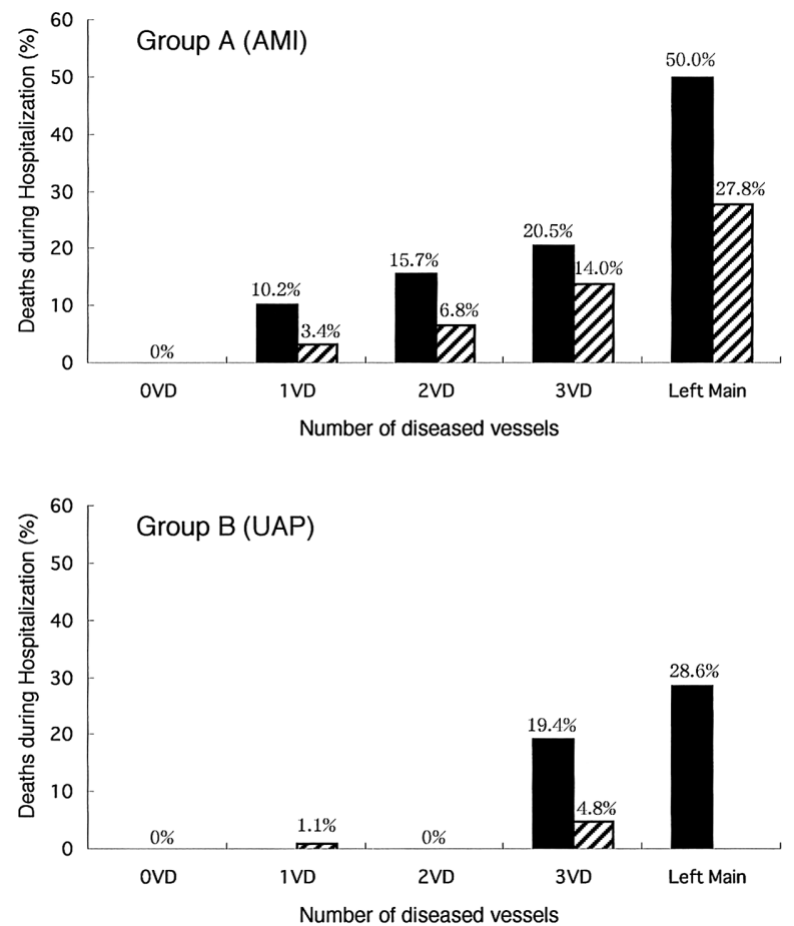

Fig 2. Rates of death during hospitalization for acute coronary syndromes among women and men, according to the number of diseased vessels and the presence of left main coronary disease. Closed bar, women; hatched bar, men. AMI, acute myocardial infarction; UAP, unstable angina pectoris. 
Table 4 Univariate Predictors of In-Hospital Mortality

\begin{tabular}{|c|c|c|c|c|}
\hline \multirow[t]{2}{*}{ Variables } & \multicolumn{2}{|c|}{$\begin{array}{c}\text { Group A } \\
\begin{array}{c}\text { (Myocardial infarction) } \\
(n=1,408)\end{array}\end{array}$} & \multicolumn{2}{|c|}{$\begin{array}{c}\text { Group B } \\
\text { (Unstable angina) } \\
(n=332)\end{array}$} \\
\hline & OR $(95 \% C I)$ & $p$ value & OR $(95 \% C I)$ & $p$ value \\
\hline Age (per 1 year) & $1.08(1.06-1.10)$ & $<0.0001$ & $1.10(1.03-1.19)$ & 0.009 \\
\hline Female gender & $2.2(1.5-3.3)$ & $<0.0001$ & $4.7(1.4-16.1)$ & 0.01 \\
\hline Smoking & $0.5(0.3-0.8)$ & 0.002 & $0.3(0.1-1.3)$ & $N S$ \\
\hline Prior myocardial infarction & $2.2(1.3-3.7)$ & 0.002 & $1.1(0.2-4.9)$ & $N S$ \\
\hline Prior congestive heart failure & $5.5(3.0-9.9)$ & $<0.0001$ & $4.7(0.9-23.8)$ & 0.06 \\
\hline Cerebrovascular disease & $2.7(1.7-4.4)$ & $<0.0001$ & $0.9(0.1-7.0)$ & $N S$ \\
\hline Killip class & & $<0.0001$ & & 0.002 \\
\hline$I$ & 1.0 & & 1.0 & \\
\hline II & $8.9(4.5-17.5)$ & & $5.5(0.6-51.8)$ & \\
\hline III & $20.8(9.4-45.6)$ & & $49.2(2.7-903.2)$ & \\
\hline IV & $40.9(22.4-74.6)$ & & $98.4(7.6-1271.3)$ & \\
\hline No. of diseased vessels & & $<0.0001$ & & $<0.0001$ \\
\hline 0 & - & & - & \\
\hline 1 & 1.0 & & 1.0 & \\
\hline 2 & $2.0(1.2-3.1)$ & & - & \\
\hline 3 & $3.9(2.5-6.1)$ & & $15.3(1.9-120.9)$ & \\
\hline Left main coronary disease & $5.0(2.5-9.9)$ & $<0.0001$ & $3.6(0.7-17.5)$ & $N S$ \\
\hline Intervention & $0.5(0.3-0.8)$ & 0.008 & $0.3(0.1-1.01)$ & 0.05 \\
\hline
\end{tabular}

OR, odds ratio; $C I$, confidence interval.

Table 5 Multivariate Predictors of In-Hospital Mortality

\begin{tabular}{|c|c|c|c|c|}
\hline \multirow[t]{2}{*}{ Variables } & \multicolumn{2}{|c|}{$\begin{array}{c}\text { Group A } \\
\begin{array}{c}\text { (Myocardial infarction) } \\
(n=1,408)\end{array}\end{array}$} & \multicolumn{2}{|c|}{$\begin{array}{c}\text { Group B } \\
(\text { Unstable angina }) \\
(n=332)\end{array}$} \\
\hline & OR $(95 \%$ CI $)$ & $p$ value & OR $(95 \% C I)$ & $p$ value \\
\hline Age (per 1 year) & $1.06(1.03-1.08)$ & $<0.0001$ & $1.004(0.92-1.01)$ & NS \\
\hline Female gender & $1.7(0.98-2.9)$ & 0.06 & $6.4(1.1-37.0)$ & 0.04 \\
\hline Prior congestive heart failure & $2.2(1.04-4.5)$ & 0.04 & $3.8(0.5-30.2)$ & $N S$ \\
\hline Prior cerebrovascular disease & $2.0(1.1-3.6)$ & 0.02 & - & \\
\hline Killip class & & $<0.0001$ & & 0.08 \\
\hline$I$ & 1.0 & & 1.0 & \\
\hline II & $5.9(2.8-12.4)$ & & $8.9(0.6-125.7)$ & \\
\hline III & $10.0(4.1-24.6)$ & & - & \\
\hline IV & $31.2(16.1-60.4)$ & & $40.9(1.5-1152.1)$ & \\
\hline No. of diseased vessels & & 0.0003 & & 0.0008 \\
\hline 0 & - & & - & \\
\hline 1 & 1.0 & & 1.0 & \\
\hline 2 & $1.5(0.9-2.6)$ & & - & \\
\hline 3 & $2.1(1.2-3.8)$ & & $10.2(0.99-104.8)$ & \\
\hline Intervention & $0.5(0.3-1.002)$ & 0.05 & $0.1(0.02-0.8)$ & 0.03 \\
\hline
\end{tabular}

OR, odds ratio; $C I$, confidence interval.

sion, ${ }^{1-7,12}$ worse hemodynamics, ${ }^{3-7}$ differences in the time of presentation, 1,13 the rates of aspirin and $\beta$-blocker usage, $1,12,14$ mechanical complications $5,12,15$ electrical complications, 1,5 thrombotic and fibrinolytic activity ${ }^{16-19}$ and reduced collateral flow ${ }^{20}$ In the present study, the women were older and had a higher rate of hypertension than the men, but the prevalence of diabetes and the hemodynamic status were not different between the 2 sexes.

\section{Number of Diseased Vessels in Women With ACS}

The angiographic characteristics of the women and men in both of the present study groups did not differ. Hochman et al reported that women with ACS had zero vessel disease more frequently than men?,8 However, we found that despite Japanese patients having a higher incidence of variant angina than Caucasian patients, the frequency of zero vessel disease in our study was lower than that reported by Hochman et al and did not differ between the sexes.
Most of the present patients $(93.0 \%)$ underwent coronary angiography in an emergency situation, so we may have underestimated the frequency of zero vessel disease because of the presence of thrombus.

\section{In-Hospital Mortality in Women With AMI}

Several studies have reported that there is no significant difference in the mortality rates between men and women for ACS after adjusting for differences in age and other prognostic factors, $2,4-6$ and our results support these earlier findings in patients with AMI. In the present group A (AMI), there were no significant difference in the mortality rate between women and men after adjusting for age, and in addition, adjusting for variables other than age did not diminish the sex difference in prognosis (data not shown). Therefore, we suggest that older age is an important factor in the higher mortality for women with AMI. 


\section{In-Hospital Mortality in Women With UAP}

Several studies have reported that the gender difference in outcome varies among the types of ACS; ;,7,8 for example, Hochman et al reported that among patients with UAP, female sex was associated with an independent protective effect? In contrast to those findings, we found that women with UAP, as well as those with AMI, had higher in-hospital mortality than men. In particular, women with UAP who had severe coronary artery disease (3-vessel disease or left main coronary artery disease) had much higher mortality relative to men. In the study of Hochman et al, the women with UAP had a lower rate of 3-vessel disease than the men, which may explain the better outcome of the women in their study. Moreover, in their study, coronary angiography and interventions were discouraged for the duration of the study-drug infusion (72h) unless there was evidence of recurrent ischemia. In contrast, most of the present patients underwent emergency coronary angiography and this difference in treatment strategy may account for the different results? 21

The reason why being female gender by itself is an independent predictor of in-hospital mortality in patients with UAP is unclear, but may relate to the poorer myocardial reserve in women suggested by diastolic dysfunction, less increase in the left ventricular ejection fraction during exercise $^{22}$ and reduced collateral blood flow? ${ }^{20}$ Moreover, 3vessel disease was an independent predictor of in-hospital mortality in patients with UAP. Therefore, a more careful and aggressive treatment strategy may be necessary to improve the outcome of female patients with UAP, especially those with severe coronary artery disease. Additional studies with a larger sample and prospective analyses are necessary to clarify the reasons why women with UAP have higher in-hospital mortality.

\section{Study Limitations}

First, we did not examine the prevalence of thrombolysis, which is the principal therapy for AMI in Western populations. Although the exact prevalence in Japan was unclear, we considered it to be low because it was very infrequently performed in the participating hospitals. Second, the prevalence of aspirin, $\beta$-blocker and angiotensin converting enzyme inhibitor use, which reduce the mortality after AMI ${ }^{23}$ were unknown. Third, we did not separate coronary angioplasty and coronary artery bypass grafting, but combined them as an intervention type. Therefore, the prevalence of each therapy is unknown. Because we only investigated the patients who died during hospitalization, 92.5\% of the interventions in both the AMI and UAP groups were coronary angioplasty. Fourth, this study is retrospective and lacks information on women for whom coronary angiography was not performed. Therefore, the women in this study may have had fewer comorbid conditions than those in whom coronary angiography was not performed.

\section{Conclusions}

Although there were no significant gender differences in the number of diseased vessels and hemodynamics, Japanese women with ACS had a higher in-hospital mortality rate than men. Older age is the potential explanation for the higher in-hospital mortality among women with AMI, whereas female gender itself may be an important predictor for those with UAP.

\section{References}

1. Vaccarino V, Parsons L, Every NR, Barron HV, Krumholtz HM. Sexbased differences in early mortality after myocardial infarction. $N$ Engl J Med 1999; 341: 217-225.

2. Maynard C, Litwin PE, Martin JS. Gender differences in the treatment and outcome of acute myocardial infarction: Results from the Myocardial Infarction Triage and Intervention Registry. Arch Intern Med 1992; 152: 972-976.

3. Kostis JB, Wilson AC, O'Dowd K, Gregory P, Chelton S, Cosgrove $\mathrm{NM}$, et al. Sex differences in the management and long-term outcome of acute myocardial infarction. Circulation 1994; 90: 1715-1730.

4. Coronado BE, Griffith JL, Beshansky JR, Selker HP. Hospital mortality in women and men with acute cardiac ischemia: A prospective multicenter study. J Am Coll Cardiol 1997; 29: 1490-1496.

5. Gottlieb S, Harpaz D, Shotan A, Boyko V, Leor J, Cohen M, et al. Sex differences in management and outcome after acute myocardial infarction in the 1990s. Circulation 2000; 102: 2484-2490.

6. Kambara H, Kinoshita M, Nakagawa M, Kawai C. Gender difference in long-term prognosis after myocardial infarction: Clinical characteristics in 1000 patients. Jpn Circ J 1995; 59: 1-10.

7. Hochman JS, Tamis JE, Thompson TD, Weaver WD, White HD, Werf FV, et al. Sex, clinical presentation, and outcome in patients with acute coronary syndromes. N Engl J Med 1999; 341: 226-232.

8. Hochman JS, McCabe CH, Stone PH, Becker RC, Cannon CP, DeFeo-Fraulini T, et al. Outcome and profile of women and men presenting with acute coronary syndrome: A report from TIMI IIIB. $J$ Am Coll Cardiol 1997; 30: 141-148.

9. Beltrame JF, Sasayama S, Maseri A. Racial heterogeneity in coronary artery vasomotor reactivity: Differences between Japanese and Caucasian patients. J Am Coll Cardiol 1999; 33: 1442-1452.

10. Pristipino C, Beltrame JF, Finocchiaro ML, Hattori R, Fujita M, Mongiardo R, et al. Major racial differences in coronary constrictor response between Japanese and Caucasians with recent myocardial infarction. Circulation 2000; 101: 1102-1108.

11. Kubota I, Ito H, Yokoyama K, Yasumura S, Tomoike H. Early mortality after acute myocardial infarction: Observational study in Yamagata. Jpn Circ J 1998; 62: 414-418.

12. Pagley PR, Yarzebski J, Goldberg R, Chen Z, Chiriboga D, Dalen P, et al. Gender differences in the treatment of patients with acute myocardial infarction. Arch Intern Med 1993; 153: 625-629.

13. Sheifer SE, Rathore SS, Gersh BJ, Weinfurt KP, Oetgen WJ, Breall JA, et al. Time to presentation with acute myocardial infarction in the elderly. Circulation 2000; 102: 1651-1656.

14. Rathore SS, Berger AK, Weinfurt KP, Feinleib M, Oetgen WJ, Gersh $\mathrm{BJ}$, et al. Race, sex, poverty, and the medical treatment of acute myocardial infarction in the elderly. Circulation 2000; 102: 642-648.

15. Lincoff AM, Califf RM, Ellis SG, Sigmon KN, Lee KL, Leimberger $\mathrm{JD}$, et al for the Thrombolysis and Angioplasty in Myocardial infarction Study Group. Thrombolytic therapy for women with myocardial infarction: Is there a gender gap? J Am Coll Cardiol 1993; 22: 1780 1787

16. Conlan MG, Folsom AR, Finch A, Davis CE, Sorlie P, Marcucci G, et al. Associations of factor VIII and von Willebrand factor with age, race, sex, and risk factors for atherosclerosis: The Atherosclerosis Risk in Communities (ARIC) study. Thromb Haemost 1993; 70: 380385.

17. Tracy RP, Bovill EG, Fried LP, Heiss G, Lee MH, Polak JF, et al. The distribution of coagulation factors VII and VIII and fibrinogen in adults over 65 years: Results from the Cardiovascular Health Study. Ann Epidemiol 1992; 2: 509-519.

18. Stegnar M, Pentek M. Fibrinolytic response to venous occlusion in healthy subjects: Relationship to age, gender, body weight, blood lipids and insulin. Thromb Res 1993; 69: 81-82.

19. Cucuianu M, Lanczek M, Roman S. Plasminogen activator inhibitor (PAI) in obese men and obese women. Rom J Intern Med 1993; 31: $183-192$.

20. Johansson S, Bergstrand R, Schlossman D, Selin K, Vedin A, Wilhelmsson C. Sex differences in cardioangiographic findings after myocardial infarction. Eur Heart J 1984; 5: 374-381.

21. Lagerqvist B, Safstrom K, Stahle E, Wallentin L, Swahn E, FRISC II Study Group Investigators. Is early invasive treatment of unstable coronary artery disease equally effective for both women and men? $J$ Am Coll Cardiol 2001; 38: 41-48.

22. Merz CN, Moriel M, Rozanski A, Klein J, Berman D. Gender-related differences in exercise ventricular function among healthy subject and patients. Am Heart J 1996; 131: 704-709.

23. Ryan TJ, Anderson JL, Antman EM, Braniff BA, Brooks NH, Califf RM, et al. ACC/AHA Guidelines for management of patients with acute myocardial infarction. J Am Coll Cardiol 1996; 28: 1328-1428. 


\section{Appendix}

Additional Participants in the Study

Ishikawa Prefectural Central Hospital (H. Kanaya, B. Kaku); Kaga Central

Hospital (Y. Kita); Kanazawa Social Insurance Hospital (M. Minamoto, M.

Nagata); Kanazawa Cardiovascular Hospital (M. Namura, T. Tsuchiya);

Keijyu General Hospital (Y.Horita); Koseiren Takaoka Hospital (K.
Shimizu); Komatsu City Hospital (K. Ueda); Saiseikai Kanazawa Hospital (T. Araki, T. Konno); Shinminato City Hospital (N. Takeda); Tatsunokuchi Hoju Memorial Hospital (S. Mori); Toyama Red Cross Hospital (Y.Nitta); Himi City Hospital (K. Misawa); Fukui Prefectural Hospital (J. Hirai); Hokuriku Hospital (H. Oiwake); Yokohama Sakae Kyosai Hospital (I. Michishita, T. Iwaki). 